mulo aos projetos de aquisiçáo de tecnologia internacional, e aplicada para financiar pesquisas nos países em desenvolvimento que se mostrassem dispostos a aumentar a competitividade de suas empresas com o apoio das universidades e centros de pesquisa. Essa proposta náo é nova. Para reforçar tal programa, seria muito bem-vinda a criaçáo de um fundo internacional devotado a suplementar os fundos locais. Uma agência - ou banco internacional - poderia ser usada com esse propósito, o que certamente contribuiria para diminuir o hiato tecnológico entre os dois mundos e evitar o pesadelo que nos ameaça.

\title{
INVESTIMENTOS EM CIÊNCIA E TeCnologia
}

\author{
ARON KUPPERMANN \\ (California Institute of Technology, Pasadena, EUA)
}

\begin{abstract}
apoio à ciência e à tecnologia em um mundo em rápida mudança está sendo fortemente escrutinizado, tanto nos países desenvolvidos como nos em desenvolvimento. Entre as questóes levantadas estão: Por que apoiar C\&T? Qual fração dos recursos da sociedade deve ser alocada para essa atividade? Como repartir esses recursos entre pesquisa básica, pesquisa aplicada e desenvolvimento tecnológico? Quais devem ser os mecanismos de apoio? Podem tais investimentos ser feitos de forma ecologicamente segura e compatível com uma sociedade sustentável? Essas são questóes duras e importantes que se procurará discutir no presente artigo. Algumas das respostas são aquelas válidas há $\mathbf{5 0}$ anos $\mathrm{e}$ têm um forte elemento de permanência. Outras estão em processo de mudança fundamental e sujeitas ao debate e análise internacionais. Este encontro é uma das várias manifestaçōes desse escrutínio realizado pela comunidade internacional de cientistas interessados, tecnólogos, educadores, economistas, sociólogos e políticos. O resultado de discussões dessa natureza deve ajudar a dar forma ao futuro deste planeta e de seus habitantes.
\end{abstract}

Por que a ciência deve ser apoiada pela sociedade? Existem muitas 
respostas para essa questão, de mais amplas a mais localizadas. A mais ampla diz ser a espécie humana essencialmente uma espécie curiosa que por milênios tem transferido um reservatório de conhecimentos de geração a geração. Seu futuro parece estar profundamente ligado à continuação desse crescimento do conhecimento e o desejo por essa continuidade está profundamente embutido na estrutura de nossos cérebros, na estrutura genética e na resultante evoluçăo das sociedades humanas. Devemos apoiar a ciência porque é parte de nossa natureza inerente. Resposta mais localizada diz que o conhecimento acerca da natureza nos permite desenvolver os meios tecnológicos necessários para melhorar nossa qualidade de vida de forma sustentável, consistente com os recursos finitos do planeta e com seu equilíbrio ecológico. Isso também responde à questáo: por que a tecnologia deve receber investimentos feitos pela sociedade.

A questão sobre qual a fração dos recursos da sociedade deve ser alocada para $C \& T$ é difícil de responder devido a argumentos ab initio, mas pode ser discutida com base na experiência passada. Existe forte correlaçáo entre a fraçáo do PIB investido em C\&T por um país e seu desenvolvimento geral. Essa fração vai de $2,6 \%$ para os países mais desenvolvidos do mundo a $0,1 \%$ para os menos desenvolvidos. Tal correlação não prova existir uma ligação de causa e efeito entre investimentos em C\&T e desenvolvimento, mas é difícil náo especular que haja algum processo de retroalimentaçáo entre essas duas variáveis, pelo qual investimentos levam a desenvolvimento e este a mais investimentos. A variável importante, em qualquer caso, parece ser não o investimento absoluto mas a fração de investimento. Isso quer dizer que países com um PIB pequeno (devido, por exemplo, à sua pequena populaçáo) têm, quando investem a mesma percentagem de seu PIB em C\&T, aproximadamente o mesmo nível de desenvolvimento que aqueles cujo PIB é significativamente maior. Isso sugere que os países em desenvolvimento devem lutar para investir uma proporçăo maior de seu PIB em C\&T. É verdade que os intensos problemas e necessidades sociais de tais países tornam política e psicologicamente difícil atingir níveis de investimento adequados. No entanto, devemos nos lembrar de que as percentagens envolvidas são pequenas - $0 \%$ comparado a $2 \%$, por exemplo - e o objetivo de tais financiamentos, a longo prazo, é fazer decrescer significativamente os problemas sociais que tornaram difícil o início dos investimentos. $O$ assunto parece dizer respeito, como no caso de muitos temas políticos e econômicos, ao balanço entre perspectivas de curto e de longo prazos.

É muito importante a questáo sobre qual fração dos investimentos da sociedade deve ser alocada para C\&T e qual para P\&D. Ela é muito 
debatida hoje, tanto no mundo desenvolvido quanto no em desenvolvimento. Nos diferentes contextos, a natureza dos argumentos é diferente, embora existam importantes elementos comuns. No mundo desenvolvido, alguns afirmam que a quantidade de conhecimento científico já disponível é mais que o suficiente para resolver os problemas que a sociedade enfrenta. Como resultado, quase todos os recursos disponíveis para C\&T devem ser alocados na aplicaçáo daquele conhecimento, objetivando a melhoria da sociedade, ou seja, investimento em $T$ (ou P\&D), menos que em C. $\mathrm{O}$ argumento é falho sob dois aspectos importantes. Primeiro, a suposição de que já possuímos suficiente conhecimento básico poderia bem ter sido feita três ou quatro décadas atrás. Ainda assim, as descobertas feitas desde entáo pela ciência básica em biologia molecular e em física do estado sólido levaram a aplicaçóes que afetam dramaticamente toda a sociedade, tanto no mundo desenvolvido como no em desenvolvimento. A verdade é que não temos como saber ao que levarão novos conhecimentos e, assim, é do maior interesse, para o mundo desenvolvido, continuar com seus investimentos em C. Em segundo lugar, corte ou diminuiçáo significativa dos investimentos em $\mathrm{C}$ pelo mundo desenvolvido váo de encontro à curiosidade humana, de que já falamos anteriormente. Se o mundo desenvolvido cortar esses investimentos, o que devemos esperar para o futuro da humanidade? $O$ efeito total pode ser uma queda significativa de seu desenvolvimento como espécie inteligente.

Nos países em desenvolvimento, o argumento diz que a ciência é uma atividade internacional sem donos. Assim, uma vez que essa atividade se tornou cara demais para eles, deixe-se que o mundo desenvolvido invista em ciência. Qualquer conhecimento básico de que os primeiros necessitem para fazer seu próprio desenvolvimento tecnológico está na literatura franca. Novamente, o argumento é falacioso em vários aspectos. Antes de mais nada, ele poderia também ser aplicado à parte $T$ de C\&T. Desenvolver novas tecnologias é caro e estas podem ser compradas do mundo desenvolvido em pacotes fechados. As dificuldades desse procedimento são já bem conhecidas, tornando muito difícil ou mesmo impossível, para os países em desenvolvimento, explorar áreas nas quais tenham vantagem competitiva e, assim, se desenvolverem como uma economia aberta. Da mesma forma, é também difícil ou impossível, para esses países, adaptar tecnologias estrangeiras às condiçöes específicas de seu meio-ambiente. Tais adaptaçóes requerem mais que conhecimento de caixas pretas e, portanto, capacidade tecnológica em recursos humanos. Tal capacitação só pode ser construída por um sistema de educação superior no qual se estude aprofundadamente o estado $\mathrm{da}$ arte em C\&T. Essa base institucional requer um investimento ade- 
quado em $\mathrm{C}$ básica, bem como em $\mathrm{T}$. Outra falácia do argumento a favor de investimento baixo ou nulo em $\mathrm{C}$ pelos países em desenvolvimento é que isso levaria à sua não-representatividade na busca internacional pelo conhecimento e à cidadania de segunda classe em uma atividade intelectual fundamental para o homem.

A conclusão é que, em países desenvolvidos, a fração da $C \& T$ devotada a $\mathrm{C}$ deve ser mantida nos níveis atuais, sem se deteriorar. Nos países em desenvolvimento, ela deve ser suficiente para garantir saudável e razoável participaçáo no empreendimento científico internacional. Além disso, a pesquisa em programas de graduação em ciência básica deve ser básica para resultar em cientistas bem treinados, mesmo que eles, depois, se engajem em trabalho aplicado. Pesquisa em programas de graduação em ciências aplicadas e em tecnologia deve ser aplicada, mas o curso associado deve ter um componente saudável de ciência básica a fim de evitar a acelerada obsolescência que ocorre a pessoal estreitamente treinado quando a tecnologia sofre uma rápida alteraçáo.

Os mecanismos para financiar as atividades de C\&T devem estar fundamentalmente baseados na distinção entre bem público e bem privado. Atividades para o bem público devem ser apoiadas por fundos públicos, enquanto as privadas, pelo setor privado. Evidentemente, existem interfaces de grande importância entre esses dois setores. Os mecanismos que governam tais atividades ainda não foram adequadamente amadurecidos nos países desenvolvidos, $\mathrm{e}$ isso deve ser o foco de sérios esforços. Nos países em desenvolvimento, o principal produto do setor público para consumo do privado é a máo-de-obra altamente treinada no estado da arte em C\&T. Essa mão-de-obra é empregada pelo setor privado na resoluçáo de seus problemas. Esse é o mecanismo mais importante de transferência de C\&rT do setor público para o privado. Os mesmos indivíduos altamente treinados, através de seus contatos com a universidade, também estabelecem um fluxo de informação na direçáo oposta, que ajuda a manter a última informada dos desenvolvimentos e necessidades da indústria. Esse fluxo bidirecional de informação deve, no entanto, ser intensificado tanto nos países desenvolvidos quanto nos em desenvolvimento. Os investimentos do setor público em C\&T devem ser efetuados através de mecanismos transparentes aos recipientes dos fundos, nos quais cuidadoso julgamento interpares seja o fator determinante para as decisóes de alocaçáo. Esse deve ser o caso tanto na universidade como nos centros de pesquisa governamentais.

Para finalizar, é importante sublinhar que náo apenas os investimentos em $\mathrm{T}$ (e em $\mathrm{C}$ ) podem ser feitos de forma ecologicamente segura, mas que este deve ser um critério central para tais investimentos. No 
passado, quando a populaçáo mundial era relativamente pequena e os recursos naturais aparentemente infinitos, praticamente náo havia consideraçáo do impacto tecnológico sobre o ambiente. Agora que a população mundial exerce forte pressão sobre o planeta, o desenvolvimento tecnológico deve ser direcionado para a utilizaçáo de recursos renováveis e para a preservação da integridade ecológica do ambiente. A consideração de tais critérios requererá maior conhecimento básico dos sistemas ecológicos e mais, náo menos, desenvolvimento tecnológico. Também vai requerer a estabilização da população mundial em um nível sustentável. Felizmente, a humanidade está apta a atingir tais objetivos; de outra forma, estaremos destinados a um baixo nível evolutivo entre as inteligências que possivelmente permeiam o universo.

\title{
DinÂMica NÃo-LinEAR, Sistemas CAÓtICOS E APLICAÇÕES
}

\author{
JACOB PALIS \\ (Instituto de Matemática Pura e Aplicada \\ CNPq, Rio de Janeiro, Brasil)
}

$\bigvee_{\text {cessos iterativos expressos em termos matemáticos por (iteraçóes }}^{\text {uitos dos fenômenos da natureza podem ser modelados por pro- }}$ de) uma transformaçáo em certo espaço de eventos, representando o caso de evolução temporal discreta ou o caso de uma evoluçáo contínua por uma equação diferencial ou um campo de vetores. Em ambas as situaçóes, processos iterativos são chamados sistemas dinâmicos. Considera-se que esse campo teve início com o grande matemático francês Henri Poincaré, há cerca de 100 anos. Mas sua origem está claramente vinculada à Mecânica Celeste e, nesse sentido, podemos mencionar Newton, Galileu e muitos outros como pioneiros.

Dentre muitas outras aplicações, tais modelos são empregados na previsão de eventos, seja a curto, seja a longo prazo. Assim, está-se freqüentemente interessado no comportamento a longo prazo das solu- 